\title{
Modelling the Effects of Population Dynamics on Solid Waste Generation and Treatment
}

\author{
Jonas Petro Senzige ${ }^{1}$, Oluwole Daniel Makinde ${ }^{2}$ \\ ${ }^{1}$ The Institute of Tax Administration, Tanzania Revenue Authority, Dar es Salaam, Tanzania \\ ${ }^{2}$ Faculty of Military Science, Stellenbosch University, Saldanha, South Africa
}

Email address:

jsenzige@tra.go.tz (J. P. Senzige),jpsenzige@yahoo.com (J. P. Senzige), makinded@gmail.com (O. D. Makinde)

\section{To cite this article:}

Jonas Petro Senzige, Oluwole Daniel Makinde. Modelling the Effects of Population Dynamics on Solid Waste Generation and Treatment. Science Journal of Applied Mathematics and Statistics. Vol. 4, No. 4, 2015, pp. 141-146. doi: 10.11648/j.sjams.20160404.14

Received: November 3, 2015; Accepted: November 13, 2015; Published: July 23, 2016

\begin{abstract}
This paper presents a mathematical model of the effects of population dynamics on solid waste generation and treatment. The model is developed by grouping the population into three age classes and each group considered to have its own solid waste generation rate and natural death rate. The population is assumed to increase due to birth and migration. Both analytical and numerical results confirm that solid waste generation increases with increasing population growth. On the other hand, sensitivity analysis shows that increasing solid waste treatment effort results in significant decreases in solid waste accumulation suggesting that with concerted treatment effort solid waste free environment can be achieved.
\end{abstract}

Keywords: Mathematical Modelling, Population Dynamics, Solid Waste Generation, Solid Waste Treatment

\section{Introduction}

Despite the fact that solid waste management is a widely research subject area, solid waste still poses a big threat to human health and the environment, especially in the developing world [1-3]. In Dar es Salaam for example, only $40 \%$ of the 4,200 tons generated daily is collected [4] and the rest find their way into trenches or river valley or are dumped in open spaces or on the road side and when it rains they clog drainage systems leading to floods. Moreover, these places become breeding grounds for vectors associated with cholera, diarrhoea and malaria diseases and through percolation these wastes affect soil fauna and sauna and hence in some way reduce soil productivity. Several factors are said to contribute to the continued piling up of solid waste along the streets. The commonly cited reasons include poor technology, weak management structure, lack of resources and uncontrolled rural-urban migration [5-12].

In an attempt to tackle the problem, several researchers have used various mathematical techniques to model solid waste generation and treatment, transportation and even resources allocation. Examples include [13-18]. All these attempts were geared at establishing the relationship between solid waste generation and management with various factors, the major aim being the understanding of the intricacies involved in order to aid in solid waste management planning. According to [13] mathematical modelling provides an insight into a problem by establishing mathematical relationships among the variables and parameters involved. Using the deterministic compartmental model [13] modelled solid waste generation and treatment and concluded that solid waste generation is dependent on population growth rate and that as solid waste treatment effort is increased solid waste accumulation decreases. In that study, population was divided into three groups of young, adults and elderly and assumed that the groups generate waste at the same rate and have the same natural death rate. Population was considered to increase due to birth and migration while the net growth rate was the difference between the recruitment rate (birth and migration) and the natural death rate.

The assumptions that the groups have the same natural death rate and that they generate solid waste at the same rate were a serious shortfall as literature $[14,19,20-21]$ indicates otherwise. This paper presents an improved version of the [13] model by assuming that each population group has its own solid generation rate and natural death rate.

\section{Model Development}

As in [13] we assume that solid waste generation rate 
increases with increasing population and population increases due to birth and migration. Similarly, the population is divided into three groups of the young $\left(\mathrm{A}_{1}\right)$, the adults $\left(\mathrm{A}_{2}\right)$ and the elderly $\left(\mathrm{A}_{3}\right)$. However, unlike in Senzige et al. (2014) where it was assumed that the three groups generate solid waste at the same rate and have the same natural death rate; in this paper solid waste generation rates are different and each group has its own natural death rate. The solid waste generation rates are $r_{1}$ for $\mathrm{A}_{1}, r_{2}$ for $\mathrm{A}_{2}$ and $r_{3}$ for $\mathrm{A}_{3}$ and the death rates are $\mu_{1}, \mu_{2}$ and $\mu_{3}$ for age groups $\mathrm{A}_{1}, \mathrm{~A}_{2}$ and $\mathrm{A}_{3}$ respectively. It is further assumed that the net population increase over a specific period of time is $p$ and $\pi_{1}$ is the proportion of $p$ that falls in age group $\mathrm{A}_{1}, \pi_{2}$ the proportion of $p$ falling in age group $\mathrm{A}_{2}$ and $\pi_{3}$ is the fraction of $p$ that goes to age group $A_{3}$. The survival rates for $A_{1}$ and $A_{2}$ are assumed to be $s_{1}$ and $s_{2}$ respectively.

The solid waste generated due to natural causes such as trees shedding leaves is termed $\mathrm{K}$. Some effort $\mathrm{E}$ is required to keep the environment clean. The effort $\mathrm{E}$ here means any measures emanating from the authorities or the community to keep their environment clean and thus it includes efforts geared towards compositing, disposal, recycling or reuse; waste to energy conversion etc. Furthermore it is assumed that effort employed at a rate $\rho$ and the solid waste natural decay rate is $\delta$. Some minimum quantity $\mathrm{Q}_{\mathrm{m}}$ of solid waste accumulated has to be allowed in the environment before the effort has to be applied. If once the effort is employed, it increases at the rate $\beta$ as solid waste increases and that due to unavailability of resources effort may decrease at a rate $\gamma$ then we have the model presented in Figure 1.

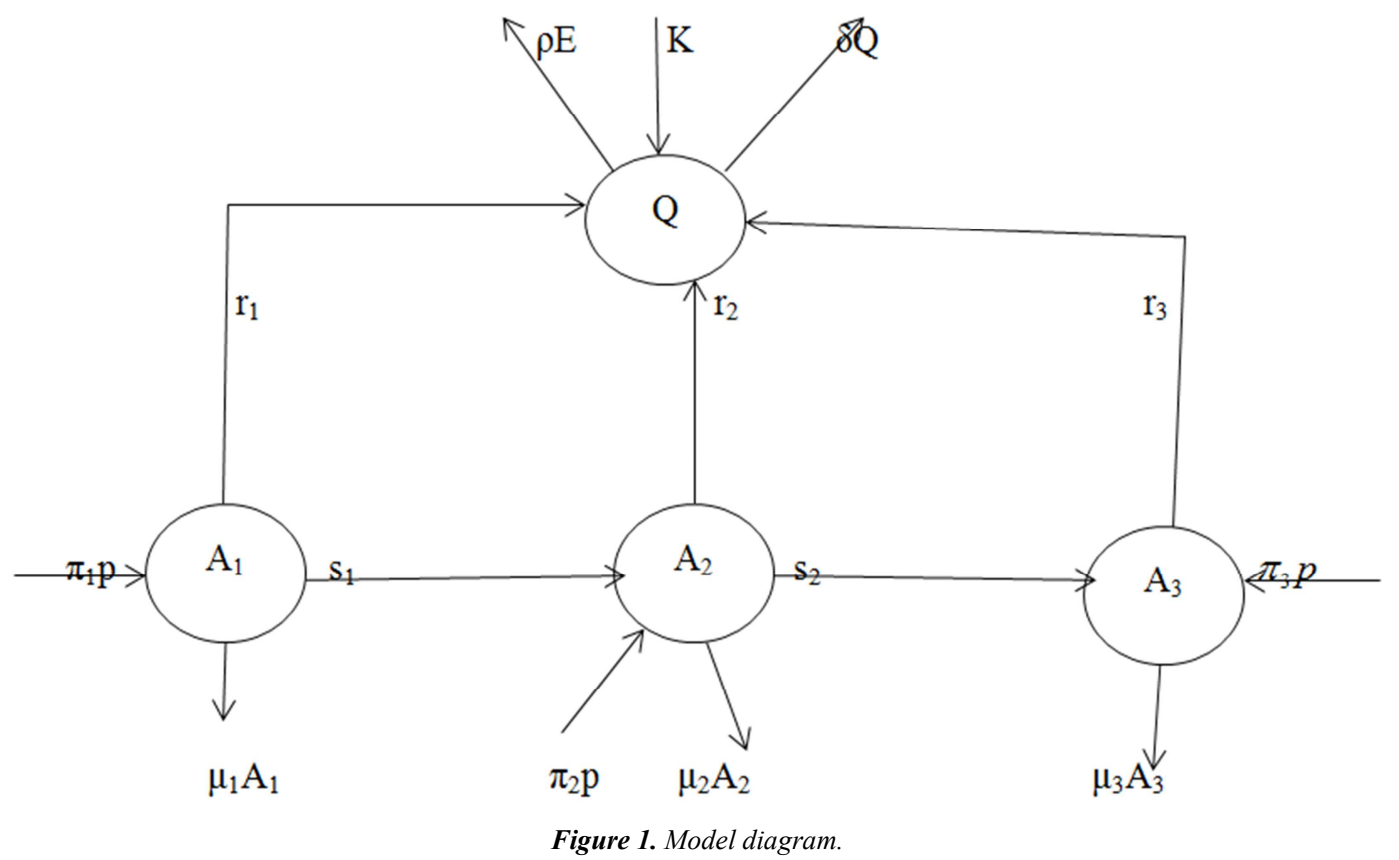

From the model in Figure 1, we have the following equations:

$$
\begin{gathered}
\frac{d A_{1}}{d t}=\pi_{1} p-s_{1} A_{1}-\mu_{1} A_{1} \\
\frac{d A_{2}}{d t}=\pi_{2} p+s_{1} A_{1}-s_{2} A_{2}-\mu_{2} A_{2} \\
\frac{d A_{3}}{d t}=\pi_{3} p+s_{2} A_{2}-\mu_{3} A_{3} \\
\frac{d Q}{d t=r_{1} A_{1}+r_{2} A_{2}+r_{3} A_{3}+K-\delta Q-\rho E} \\
\frac{d E}{d t}=\beta\left(Q-Q_{m}\right)-\gamma E
\end{gathered}
$$

\subsection{Equilibrium Point}

To find the equilibrium point we equate equations (1)-(5) to zero and solve. Therefore we have:

$$
\left.\begin{array}{l}
A_{1}^{*}=\frac{\pi_{1} p}{\left(s_{1}+\mu_{1}\right)} \\
A_{2}^{*}=\frac{\pi_{2}\left(s_{1}+\mu_{1}\right)+\pi_{2} p}{\left(s_{1}+\mu 1\right)\left(s_{2}+\mu_{2}\right)} \\
A_{3}^{*}=\frac{\pi_{3} p}{\mu_{3}}+\frac{\pi_{2} s_{2} p}{\mu_{3}\left(s_{2}+\mu_{2}\right)}+\frac{\pi_{1} s_{2} p}{\mu_{3}\left(s_{1}+\mu 1\right)\left(s_{2}+\mu_{2}\right)} \\
Q^{*}=\frac{r_{1} A_{1}+r_{2} A_{2}+r_{3} A_{3}-\rho E}{\delta} \\
E^{*}=\frac{\beta}{\gamma}\left(Q^{*}-Q_{m}\right)
\end{array}\right\}
$$


Thus, the endemic equilibrium point $H_{l}$ is given by equation (6). This is the point at which solid waste will be scattered everywhere and causing menace to the people and environment.

\subsection{Stability Analysis}

We employ the Jacobean Matrix to calculate eigenvalues. The Jacobean matrix is given by:

$$
J=\frac{\partial\left(f_{1}, f_{2}, f_{3}, f_{4}, f_{5}\right)}{\partial\left(A_{1}, A_{2}, A_{3}, Q E\right)}=\left[\begin{array}{lllll}
-s_{1}-\mu_{1} & 0 & 0 & 0 & 0 \\
s_{1} & -\mu_{2} & 0 & 0 & 0 \\
0 & s_{2} & -\mu_{3} & 0 & 0 \\
r_{1} & r_{2} & r_{3} & -\delta & -\rho \\
0 & 0 & 0 & \beta & -\gamma
\end{array}\right]
$$

Solving the characteristic equation $|J-\lambda I|=0$ gives

$$
\lambda_{1}=-s_{1}-\mu_{1}, \lambda_{2}=-\mu_{2}, \lambda_{3}=-\mu_{3}
$$

And

$$
\lambda^{2}+(\delta+\gamma) \lambda+\delta \gamma+\beta \rho
$$

Now from Routh-Hurwitz criteria [23]

$$
\delta+\gamma>0 \text { and } \delta \gamma+\beta \rho>0
$$

For the solid waste endemic equilibrium $H_{1}=\left(A_{1}^{*}, A_{2}^{*}, A_{3}^{*}, Q^{*}, E^{*}\right)$ to be stable all eigenvalue of the Jacobean matrix must be strictly negative. Clearly the eigenvalues in (8) are all negative. In addition, the RouthHurwitz criterion in (10) confirms that the other two eigenvalues are negative. Hence the solid waste endemic equilibrium

$$
H_{1}=\left(A_{1}^{*}, A_{2}^{*}, A_{3}^{*}, Q^{*}, E^{*}\right) \text { is stable. }
$$

However, we assumed that there is a threshold quantity $\mathrm{Q}_{\mathrm{m}}$ which is allowed by the authorities above which the effort $\mathrm{E}$ must be applied. This means that if $\mathrm{Q}<\mathrm{Q}_{\mathrm{m}}, \frac{d E}{d t}<0$ and when $\mathrm{Q}>\mathrm{Q}_{\mathrm{m}}, \frac{d E}{d t}>0$.

Theorem: If $A_{1}(0), \mathrm{A}_{2}(0), \mathrm{A}_{3}(0), Q(0)$ and $E(0)$, are nonnegative, then so are $A_{1}(t), \mathrm{A}_{2}(t), \mathrm{A}_{3}(t), Q(t)$ and $E(t)$ for all $t>0$. Moreover

$$
\lim _{t \rightarrow \infty} Q(t) \leq Q^{*}, \lim _{t \rightarrow \infty} E(t) \leq E^{*}
$$

Where

$$
Q^{*}=\frac{K+r_{1} A_{1}+r_{2} A_{2}+r_{3} A_{3}-\rho E}{\delta}, E^{*}=\frac{\beta}{\gamma}\left[Q^{*}-Q_{m}\right] .
$$

That is, the region

$$
\mathrm{D}=\left\{\left(A_{1}, A_{2}, A_{3}, Q, E\right) \in \mathfrak{R}_{+}^{5}: Q \leq Q^{*}, E \leq E *\right\}
$$

But for solid waste free equilibrium $Q \leq Q_{m}$. In this case, $H_{1}$ is unstable and solid waste free equilibrium $H_{0}=\left(A_{1}^{*}, A_{2}^{*}, A_{1}^{*}, 0,0\right)$ is stable. This means that all solid wastes decay to zero and no treatment effort will be required.

\subsection{Parameter Estimation}

Based on the 2012 population and housing census the projected population of Dar es Salaam 2014 gives the net migration rate as 2.43 for every one thousand (1000) individuals and the crude birth rate as 28.6 for every thousand(1000) people. Assuming the migrants are the adults and elderly, then the increase due to birth is approximately 0.03 for every individual. This means that $\pi_{1}=0.03$. If it is further assumed that $60 \%$ of the migrants are adults $(15-60$ years old), then we have $\pi_{2}=0.002$ and hence $\pi_{3}=0.001$. In summary, $\pi_{1}=0.03, \pi_{2}=0.002$ and $\pi_{3}=0.001$.

Different age groups generate waste at different rates [14, 19 and 21]. In a study that examined household behaviour under alternative pay-as -you-throw systems for solid waste disposal [24] observed that the amount of waste increased considerably with the number of small children and adults between the age group 25 to 64 years. According to [20] there is significant positive correlation of a high amount of original food within residual waste from households and a high proportion of persons aged between 20 and 59 on one hand and a less food wastage for people older than 50 years of age. Similarly, in their study to identify the parameters that explain the present situation and to assess the future amount of municipal solid waste generated per capita in different European cities [14] found out that a positive relationship existed between the percentage of the medium age group (15-59) and municipal solid waste generation. These conclusions are also supported by [21] whose study termed "A Situational Assessment of Socioeconomic Factors Affecting Solid Waste Generation and Composition in Freetown, Sierra Leone" concluded that as the average family age increases garbage generation decreases. Although these studies do not say exactly which population group generates waste at what rate, it is prudent to conclude that younger population groups generate waste at higher rates compared to the elderly. For the purpose of this work let's assume that $r_{1}=0.45, r_{2}=0.4$ and $r_{3}=0.15$.

According to [27] Tanzania's overall under-five mortality rate is 0.1325 and the adult mortality rate age $15-60$ years is 0.329 [27]. However, no available data on mortality rate for ages 5-14 and above sixty years of age. Therefore, the death rate $\mu_{1}$ for ages $0-14$ year's old group is estimated based on the under-five mortality rate. Similarly, the death rate $\mu_{3}$ for the elderly group ( $>60$ years) is estimated based on life expectancy and the adult (15-60) mortality rate. Hence $\mu_{1}=0.15, \mu_{2}=0.329$ and $\mu_{3}=0.4$

\section{Results and Discussion}

The analysis of the Jacobean matrix in equation (5.7) show that all eigenvalues are negative and therefore solid waste

positively invariant. 
endemic equilibrium is obtained at $H_{1}=\left(A_{1}^{*}, A_{2}^{*}, A_{3}^{*}, Q^{*}, E^{*}\right)$. However, if $\mathrm{Q}<\mathrm{Q}_{\mathrm{m}}$ meaning $\frac{d E}{d t}<0$ then the solid waste free equilibrium can be obtained at $H_{0}=\left(A_{1}^{*}, A_{2}^{*}, A_{1}^{*}, 0,0\right)$ can and no effort will be required to manage the solid waste.

The numerical results of the model based on the various parameters embedded in the model system on the solid waste generation and treatment as the population grows confirm the analytical results. For numerical simulation, the following parameter values $\gamma=0.005 ; \delta=0.05 ; \rho=0.05 ; \mathrm{K}=1000 ; \mathrm{S}_{1}$ $=\frac{1}{15} ; \mathrm{S}_{2}=\frac{1}{45} ; \pi_{1}=0.030 ; \pi_{2}=0.002 ; \pi_{3}=0.001 ; \mathrm{p}=$ $135000 ; r_{1}=0.45, r_{2}=0.40, r_{3}, 0.15 ; \beta=0.0055$ are utilised to examine the behaviour of the model. The initial values are $A_{1}$
$=10000, \mathrm{~A}_{2}=5000, \mathrm{~A}_{3}=1000, \mathrm{Q}=100, \mathrm{E}=100$.

Figure 2 shows the population dynamics within the community. Each group (young, adults and the elderly) will grow independent of the other until it reaches a stable state. Of course the growth id dependent on the initial population and the survival rate to the next group with time. An interpretation of this trend is that solid waste generation for each group will initially increase but as each group comes to a steady state the solid generation rate becomes constant. Figure 3 shows the effects of increasing treatment rate on the total solid waste generation. This is in agreement with what one would intuitively expect. Notably, as treatment rate increases the solid waste quantity decreases and eventually the two quantities intersect at a point and both reach a steady state.

Table 1. Summary and description of the parameters.

\begin{tabular}{llll}
\hline Parameter & Value & & Source \\
\hline $\mathrm{P}$ & 135000 & Net population growth per year & Computed based on 2014 population projection [28] \\
$\pi_{1}$ & 0.030 & Rate of recruitment in $\mathrm{A}_{1}$ & Projected 2014 net birth rate [28] \\
$\pi_{2}$ & 0.002 & Rate of recruitment in $\mathrm{A}_{2}$ & 2014 projected net migration rate [28] \\
$\pi_{3}$ & 0.001 & Rate of recruitment in $\mathrm{A}_{3}$ & 2014 projected net migration rate [28] \\
$r_{1}$ & 0.450 & Solid waste generation rate by $\mathrm{A}_{1}$ & Estimated \\
$r_{2}$ & 0.400 & Solid waste generation rate by $\mathrm{A}_{2}$ & Estimated \\
$r_{3}$ & 0.150 & Solid waste generation rate by $\mathrm{A}_{3}$ & Estimated \\
$\mu_{1}$ & 0.150 & Death rate for $\mathrm{A}_{1}$ & Estimated based on the under 5 death rate [28] \\
$\mu_{2}$ & 0.329 & Death rate for $\mathrm{A}_{1}$ & $15-60$ year olds death rate [27] \\
$\mu_{3}$ & 0.400 & Death rate for $\mathrm{A}_{1}$ & Estimated death rate for old than 60 \\
$\rho$ & 0.05 & Solid waste decreasing rate due to effort & Estimated \\
$\delta$ & 0.05 & Solid waste natural decay rate & Estimated \\
$\gamma$ & 0.005 & Effort decay rate & Estimated \\
$\beta$ & 0.0055 & Effort increase rate & Estimated \\
$\mathrm{K}$ & 1000 & Waste generated naturally & Estimated \\
$\mathrm{S}_{1}$ & $1 / 15$ & Survival rate for $\mathrm{A}_{1}$ & Reciprocal of class interval (0-14) \\
$\mathrm{S}_{2}$ & $1 / 45$ & Survival rate for $\mathrm{A}_{2}$ & Reciprocal of class interval (15-60) \\
\hline
\end{tabular}

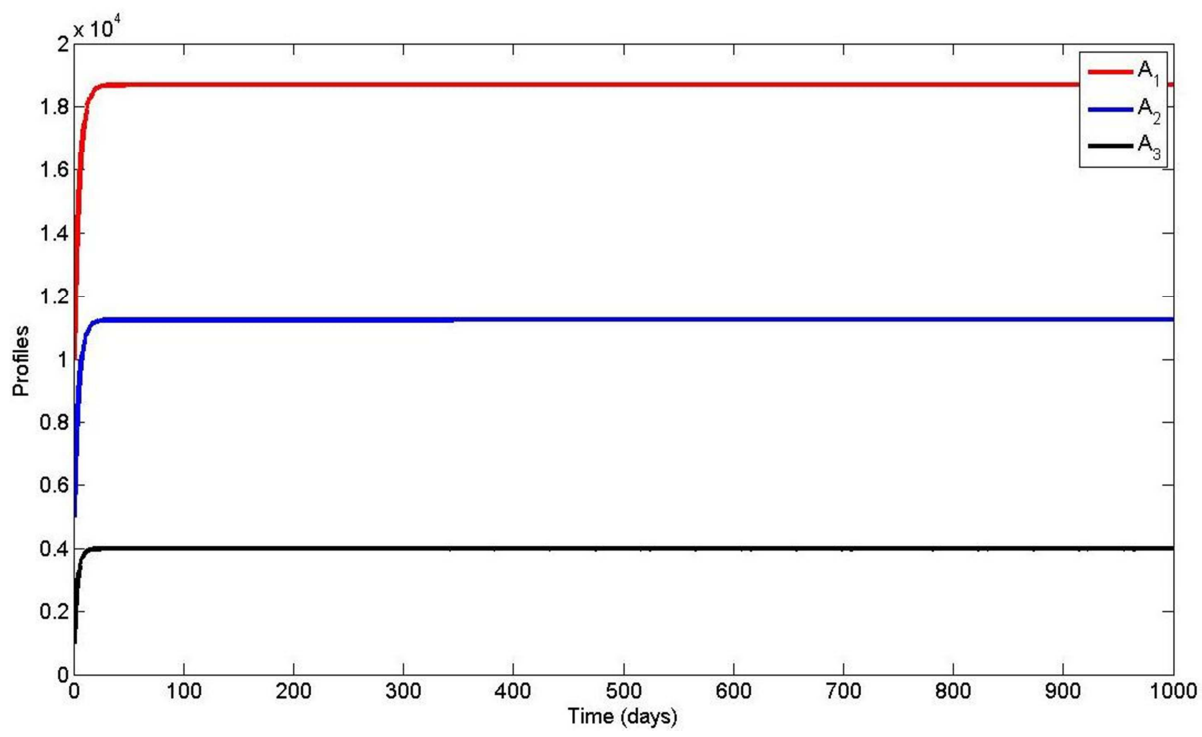

Figure 2. Population dynamics of the three groups. 


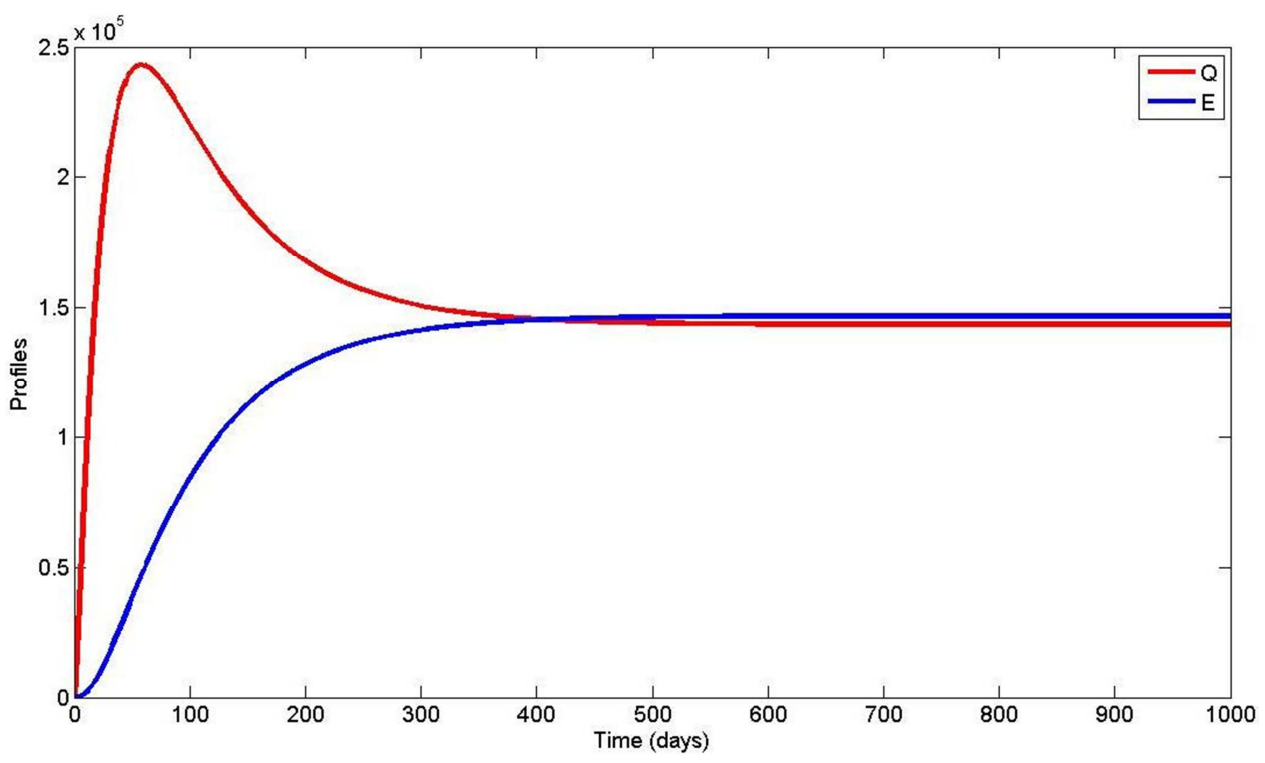

Figure 3. The effect of Effort $E$ on solid waste quantity $Q$.

In essence, at this point solid waste accumulated equals treatment. This means that all solid waste generated is treated and solid waste free equilibrium is achieved. This confirms the analytical results. In this context treatment means all methods and techniques (landfilling, composting, recycling, reuse, waste to energy conversions etc.) geared towards ensuring that the community gets rid of the menace emanating from solid waste accumulation.

The from the numerical simulation as indicated in figure 2 and figure 3 are in agreement with the results shown in Table 2. The table provides sensitivity analysis of the solid waste quantity Q and the effort applied E. The table shows how the two quantities respond to a small change in each parameter.

Table 2. Sensitivity analysis of $Q$ and $E$.

\begin{tabular}{lll}
\hline Parameter & Effect on Q & Effect on E \\
\hline$\rho$ & $-0.02 \%$ & Decrease \\
$\delta$ & $-29.98 \%$ & decrease \\
$\gamma$ & $261.98 \%$ & $-261.98 \%$ \\
$\beta$ & $-285.5 \%$ & $285.5 \%$ \\
$r_{1}$ & increase \\
$r_{2}$ & $2 \%$ & increase \\
$r_{3}$ & $1 \%$ & increase \\
$\mu_{1}$ & $0.2 \%$ & Decreases \\
$\mu_{2}$ & Decreases & Decreases \\
$\mu_{3}$ & Decreases & Decreases \\
$\pi_{1}$ & Decreases & Increases \\
$\pi_{2}$ & Increases & Increases \\
$\pi_{3}$ & Increases & Increases \\
\hline
\end{tabular}

Table 2 presents the effect of a small increase in each of the parameters on solid waste accumulation $Q$ and the treatment effort $\mathrm{E}$. The computed numerical values in the table are for parameters directly involved in computing $\mathrm{Q}^{*}$ and $E^{*}$, that is the values of $Q$ and $E$ at equilibrium point. They indicate the percentage changes in $\mathrm{Q}$ and $\mathrm{E}$ when there is an increase of 0.001 in each of the parameters. We note that such a small change in natural decay rate $\delta$ results in decrease of $\mathrm{Q}$ of about $30 \%$. It is also observed that by increasing solid waste generation rates $\left(r_{1}, r_{2}, r_{3}\right)$ solid waste increases though by small percentages. On the other hand the small $(0.001)$ increase in the effort growth rate increases the effort by about $286 \%$ which means that solid waste accumulation decreases by the same amount. However, that same increase in the effort decay rate $\gamma$ decreases the effort by about $262 \%$. Conversely, solid waste accumulation increases by the same percentage. The non-numerical effects in Table 2 are deduced intuitively from the effect the parameters involved will have on population growth and hence solid waste generation.

\section{Conclusion}

The numerical simulation results are in agreement with the analytical results. As the population grows so does solid waste accumulation until the threshold quantity allowed by the community before effort is expended is reached. But as effort is increased, solid waste accumulation decreases and eventually equals the amount of solid waste treated. This results in a solid waste free equilibrium. We noted from sensitivity analysis that a small change in natural decay rate decreases solid waste by $30 \%$. This means that if some biological processes that can help in increasing the natural decay rate are employed, the authorities involved in solid waste management will require fewer resources to manage the waste as most of the waste will decay naturally. Evidently, an increase in solid waste treatment rate decreases solid waste accumulation. Therefore it is important for the authorities to encourage community initiatives focusing on compositing, recycling, reuse and waste to energy conversion so that manageable solid waste quantity remains for disposal. The small change in effort rate $\beta$ that results in huge decrease in solid waste accumulation means that solid waste treatment 
effort should be concerted if people expect live in a solid waste free environment. Lastly, the difference in the death rates or solid waste generation rates for the three groups is immaterial as the results are similar to those obtained by [13] where the natural death rates were the same and the solid waste generation rates were not different.

\section{References}

[1] Joseph K (2002) Perspectives of Solid Waste Management in India. Proceedings of the International Symposium on the Technology and Management of the Treatment \& Reuse.

[2] African Development Bank (2002). Study on the Waste Management Options for Africa. Unpublished Report.

[3] Achankeng, E. (2003). Globalisation, Urbanisation and Municipality Solid Waste management in Africa In Proceedings of the African studies Association of Australasia and the Pacific: Africa on a Global Stage, 3-5 October, 2003 Adelaide; Australia.

[4] World Bank 2012. Municipal Solid Waste Management in Dar Es Salaam. Unpublished report.

[5] Kaare S (2002) The Role of Privatisation in Providing the Urban Poor Access to Social Services: The Case of Solid Waste Collection in Dar-es-Salaam, Tanzania In Research on Poverty Alleviation. Dar-es-Salaam Tanzania. Mkuki na Nyota Publishers Ltd.

[6] Manga VE, Forton OT and Read AD (2008). Waste management in Cameroon: A new policy.

[7] Oosterveer P and Van Vliet B (2010). Environmental systems and local actors: decentralising environmental management in Uganda. Environmental Management 45: 284-295.

[8] Okot-Okumu J and Nyenje R (2011) Municipal solid waste management under decentralisation in Uganda. Habital International 35, 537-543.

[9] Yhdego M (1995). Urban solid waste management in Tanzania: issues, concepts and challenges. Resource, Conservation and Recycling, 14 (1), 1-10.

[10] Kyessi A and Mwakalinga V (2009). GIS Application in Coordinating Solid Waste Collection: The Case of Sinza Neighbourhood in Kinondoni Municipality, Dar-es-Salaam City, Tanzania. FIG Working Week 2009: Surveyors Key Role in Accelerated Development. Eilat, Israel, 3-8 May 2009.

[11] Gawaikar V and Deshpande V. P (2006). Source Specific Quantification and Characterisation of Municipal Solid Waste - a Review. Indian Journal of Environment Vol. 86.
[12] Troscinetz and Mihelcic, (2008). Sustainable recycling of municipal solid waste in developing countries. Waste Management 29: 915-923.

[13] Senzige, J. P; Makinde, O. D; Njau, K. N; Nkansha-Gyekye, Y. (2014). Computational Dynamics of Solid Waste Generation and Treatment in the Presence of Population Growth. Asian Journal of Mathematics and Applications. Volume 2014

[14] Beigl, P., Lebersorger, S., Salhofer S., (2008). Modelling municipal solid waste generation: A review. Waste Management 28: 200-214.

[15] Benítez, S. O., Lozano-Olvera, G., Morelos, R. A., Armijo de Vega, C. (2008), Mathematical Modeling to Predict Residential Solid Waste Generation, Waste Management 28 S7-S13.

[16] Najm, M. A and El-Fadel, M., (2004). Computer-based interface for an integrated solid waste management optimisation model. Environmental Modelling and Software 19: $1151-1164$.

[17] Dyson, B and Chang N. B., (2005). Forecasting solid waste generation in a fast-growing urban region with system dynamics modelling. Waste Management 25: 669-679.

[18] Eleyan, D., Al-Khatib, I. A, Garfield, J., (2013). System dynamics model for hospital waste characterization and generation in developing countries. Waste Management and Research 31 (10) 986-995.

[19] Van Houtven G. L and Morris G. E (199). Household Bahaviour under Alternative Pay-as-You-Throw System for Solid Waste Disposal. Land Economics vol. 75 issue 4 pp 515-537.

[20] Wassermann, G. and Schneider, F. 2005. Edibles in Household Waste. Proceedings of the Tenth International Waste Management and Landfill Symposium, CISA, S. Margherita di Pula, Sardinia: 913-914.

[21] Sankoh, F. P, F. P., Yan, X., Conteh, H. A. M. (42). A Situational Assessment of Socioeconomic Factors Affecting Solid Waste Generation and Composition in Freetown, Sierra Leone. Journal of Environmental Protection, 2012, 3, 563568 .

[22] United Nations (2012) The Millennium Development Goals Report 2012. New York: UN. Available at ttp://mdgs.un.org/unsd/mdg/Resources/Static/Products/Progre ss2012/English2012.pdf

[23] Arrowsmith, D. K., Place, C. M. (1982). Ordinary differential equations: A Qualitative Approach with Applications (Chapman and Hall mathematics series). 